\begin{tabular}{|c|c|}
\hline Овечкина Я.В. & $\begin{array}{l}\text { ОСОБЕННОСТИ ОРГАНИЗАЦИИ } \\
\text { ТРУДОВОЙ ДЕЯТЕЛЬНОСТИ } \\
\text { СОВРЕМЕННЫХ ДАУНШИИТЕРОВ }\end{array}$ \\
\hline $\begin{array}{r}\text { аспирант } \\
\text { Северо-Западный инст } \\
\text { государствен } \\
\text { Средний п } \\
\text { Эле }\end{array}$ & $\begin{array}{l}\text { ина Яна Вадимовна, } \\
\text { оы социологии и социальной работы } \\
\text { тения Российской академии народного хозяйства и } \\
\text { I при Президенте Российской Федерации } \\
\text { 7/43, Санкт-Петербург, 199178, Россия } \\
\text { дрес: yanaovechkina@gmail.com }\end{array}$ \\
\hline
\end{tabular}

\title{
Аннотация
}

$\mathrm{B}^{\mathrm{c}}$ статье рассматривается позиция дауншифтеров на рынке труда и в социальной структуре российского общества. Анализируется специфика карьерной стратегии. Под «дауншифтингом» понимается явление добровольной нисходящей вертикальной социальной мобильности, характеризующееся добровольным долгосрочным изменением стиля повседневной жизни, которое может проявляться в изменении трудовой занятости, повседневных практик, социальной и географической мобильности. В рамках концепции индивидуализации дауншифтинг представлен как дестандартизованная модель биографии, предполагающая отказ от типичных для данного общества этапов, фаз жизненного цикла. Приводятся результаты глубинных интервью с дауншифтерами, позволяющие проанализировать образ жизни, «выходящий за рамки» стиля жизни в общества потребления. Внимание сосредоточено на двух важных характеристиках стиля жизни дауншифтеров: организации труда и решении финансовых вопросов. Результаты исследования показывают, что дауншифтеры - яркий пример не стандартизированной занятости и индивидуализированной карьеры. Результаты авторского исследования позволяют описать сценарии развития жизни дауншифтеров после принятого ими решения, позволяют описать особенности новых форм трудового поведения.

Хлючевые слова: дауншифтинг; социология труда; добровольная нисходящая Х вертикальная мобильность; индивидуализация стиля жизни; стиль жизни; фриланс; общество потребления. 


\title{
Ovechkina Y.V.
}

\section{LABOR PROPERTIES \\ OF MODERN DOWNSHIFTERS}

\section{Ovechkina Yana Vadimovna,}

Post-graduate student

Chair of Sociology and Social Work North-West Institute of Management

57/43, Sredniy prospect Vasilyevsky Island, Saint-Petersburg, 199178, Russia

E-mail:yanaovechkina@gmail.com

\begin{abstract}
Abstrakt
T his article provides an analysis concerning the position of downshifters in the labor market and social structure of modern Russian society. The specifics of career strategy are also being examined. «Downshifting» is understood as a phenomenon of voluntary downward vertical social mobility, characterised by voluntary long-term change of style in everyday life, which can manifest itself in the change of employment, everyday practices, social and geographical mobility. Within the concept of individualization downshifting presented as destandartised model of biography, implying the rejection of typical for a given society stages, phases of the life cycle. The results of the in-depth interviews with downshifters which were needs to better understand and analyze the «beyond» lifestyle in a consumer society. We focus on two important characteristics of the lifestyle of downshifters: labor organization and financial issues. The results reveal that downshifters is a prime example of non-standard, individualized employment and career. The results of the study allow us to describe the scenarios of the development of life of downshifters after the decision they made and the features of new forms of labor behavior.
\end{abstract}

Keywords: downshifting; sociology of work; voluntary downward vertical mobility; indiKvidualization of lifestyles; lifestyle; freelancing; «Consumer society». 
Движение дауншифтинга (англ. downshifting, переключение автомобиля на более низкую передачу, а также замедление или ослабление какого-либо процесса) распространилось на рубеже XX-XXI вв. в странах Запада как добровольное долгосрочное изменение стиля повседневной жизни, которое может проявляться в изменении трудовой занятости, повседневньх практик, социальной и географической мобильности [10]. Последователи этой идеологии исповедают уход от общепринятых общественньх ценностей: высоких чинов, вертикального продвижения по службе и прочих материальньх благ, переход к более простой жизни. В США, Австралии, в европейских странах явление дауншифтинга уже не ново, социологи изучают причины и последствия такого вида антиконсьюмеристского стиля жизни.

В 1990-х гт. в научном сообществе начинают появляться обсуждения изменений, происходящих в экономике, а также их последствий. Один из прогнозов заключался в смене «работника организации» независимым работником, занятость которого не будет связана с конкретной фирмой или компанией, а обеспечение доходов, выстраивание карьеры и профессиональная реализация будут решаться им самостоятельно. Модель стандартных трудовых отношений, для которой характерна стабильность и полная занятость, будет постепенно вытесняться гибкими формами найма и нестандартной занятостью $[1,3,6]$.

Сегодня, изучая практики дауншифтинга, нестандартной занятости, фриланса, возникает вопрос: «Почему люди выбирают занятость не в организации, обеспечивающей стабильность и защищенность, а самостоятельно выстраивают трудовую стратегию, биографию с ее рисками и неопределенностью?» И ответ на этот вопрос можно получить, определив, какие ценности разделяет эта группа, как и при помощи каких тактик, они выстраивают свое поведение, трудовую деятельность и что представляет успех в их понимании.

Необходимо заметить, что в США, Великобритании и Австралии были проведены социологические исследования, направленные на описание сообщества дауншифтеров $[8,9,11]$. В России подобные исследования ранее не проводились. Несмотря на многие сложности, которые возникают в процессе исследования явления дауншифтинга в России, большинство авторов, занимающихся данной проблематикой, сходятся во мнении - дальнейшее изучение фе- номена дауншифтинга представляет интерес. «Дауншифтинг по-русски" имеет отличительные черты, обусловленные экономическими, социальными и психологическими факторами.

Результаты исследования, приведенные в данной статье помогут приблизиться к пониманию особенностей образа жизни российских дауншифтеров, а именно специфики их трудовой деятельности. Фокусом авторского исследования является стиль жизни, выходящий за рамки «обычного» или "нормального» для общества массового потребления. С целью описания механизмов формирования и особенностей потребительского ретретизма, были проанализированы случаи сознательного изменения стиля жизни. В первую очередь нас интересовали случаи индивидуальной вертикальной социальной мобильности в направлении «сверху вниз» (например, переход на менее оплачиваемую должность). Анализ интервью был сосредоточен на построении и реализации альтернативного стиля профессиональной деятельности.

Всего в опросе поучаствовало 170 человек из них 50 дали согласие на участие в полуформализованном интервью посредством программы skype, с согласия участников велась запись разговора. Период проведения исследования май-начало июня 2014 г.

Возраст самого младшего респондента составил 25 лет, самого старшего 46 лет. Всего собрано 50 глубинных интервью с представителями сообщества дауншифтеров. На основе анализа интервью мы смогли описать способы реализации трудовых практик современньх дауншифтеров.

Прежде всего, дауншифтинг связан с изменением профессиональной деятельности: переходом на работу с более низким уровнем оплаты и или вообще кардинальной сменой сферы деятельности. По результатам интервью можно сделать вывод, что болњшинство приверженцев дауншифтинга перешли на свободную занятость, или фриланс, - выполнение работы без заключения долговременного договора с работодателем, часто дистанционно, либо найм только для выполнения определённого перечня работ [5]. Рассматривая фриланс как особьй стиль жизни, укажем, что его основу составляют ценности, разделяемые «свободными агентами», а именно - свобода, возможность оставаться самим собой, ответственность и собственные критерии успеха [4, с. 57]. Обозначая свободу как «первый компонент трудовой этики свободных агентов», Д. Пинк считает, 
что наивысшей формой её проявления является возможность «поступать по своей воле» [4, c. 72-73].

Как показало наше исследование, основным принципом организации труда для дауншифтеров является свобода как автономность, независимость работника в выборе заказчиков, проектов, режима работы, формировании стоимости, заработной платы.

Именно свобода является осью, определяющей и практики занятости, и особенности образа жизни дауншифтеров, их приоритеты, мотивацию. Но понимание свободы неодинаково, дауншифтеры воспринимают ее по-разному, например, как мобильность, как разнообразие, как гибкость графика, как отсутствие контроля, как возможность заниматься тем, что интересHo.

На основе интервью выделены следующие мотивы ухода в «свободное плавание»: независимость, творческая самореализация, наличие свободного времени и возможность организовать свой досуг, отпуск и, главное, взаимоотношения с близкими, семьей:

«Ты сам себе хозяин... можно какие-то вещи ставить на первый план, а работу все-таки на второй» (Михаил, 40 лет, переехал из Санкт-Петербурга в поселок Лен.области в 2011 году, в «прошлой жизни» владелец собственного бизнеса, в настоящий момент художник).

«Я занимаюсь разработкой и раскруткой веб-сайтов. Еще, когда я стал фрилансером, я понял, что в Москве меня почти ничего не держит, а жизнь за городом с интернетом имеет массу преимуществ. Удивительно, но у моей жены было такое же мнение, и когда у нас появились деньги, мы решили купить дом в селе и переехать туда на постоянное жительство» (Алексей, 27 лет, переехал в 2013 г из Санкт-Петербурга в Лен.область, вэб-мастер).

Благодаря современньп технологиям и Интернету появляется возможность трудовой мобильности, связанной с переменой места жительства, очень важной для организации трудовой деятельности дауншифтеров:

«Многие жители крупных городов просто мечтают о таком прекрасном зеленом офисе. И современные технологии дают возможность наслаждаться путешествиями, отдьхом около природы, в деревне или на даче» (Дмитрий, 32 года, переехал из Москвы в Алтайский край в 2012 году для ухода за престарелыми родителями, решил остаться, в прошлом вэб-дизанер, на данный момент фрилансер).
«Все, что нужно - это телефон, ноутбук и модем... Современные технологии позволяют подключаться к сети намного быстрее и проще даже с дальней дачи. Так что за окном будут ивести деревья, вокруг будет свежии воздух почти все время, которое вы будете работать. А все остальное время можно и природой наслаждаться» (Вадим, 43 года, переехал вместе с семъёй (жена и двое детей) из Санкт-Петербурга в посёлок Лен.области в 2010 году, ранее владелец собственного бизнеса, на данный момент «свободный» бизнес-консультант).

Некоторые респонденты характеризую свою прошлую работу как «бег в колесе», дауншифтинг стал для них побегом из круга «заработок-потребление»:

"Если вы считаете, что на 20 тыс. прожить нельзя - у вас психология, внушенная моделью бессмысленного потребления... сейчас больиинство - это просто винтики в бессмысленной корпоративной системе, они как белка в колесе - бегут и бегут на месте...» (Анатолий, 40 лет, проживает в Москве, ранее руководитель отдела продаж, с 2011 года в «затянувшемся отпуске» (цитата интервьюируемого).

Возможность делать так, как человек считает нужным, и быть таким, каким он сам себя ощущает - важное преимущество. Дауншифтеры склонны формировать собственный стиль трудовой деятельности: кто-то продолжает работать по профессии, просто меняя график и сбавляя темп, кто-то кардинально меняет род деятельности, кто-то превращает своё хобби в профессию и зарабатывает на этом деньги:

"К дауниифтингу я отноиусь с больиим уважением. Не к крайним случаям а-ля "уехать в Гоа и ничего не делать", а именно либо как к длиннюшим перерывам от работы, либо выборе менее стрессовой работы поближе $к$ дому, либо к занятию любимъмм делом - пусть менее доходнъмм, чем работа на корпорацию» (Татьяна, 30 лет, г. Санкт-Петербург до 2013 года ведущий менеджер крупной пивоваренной компании, на данный момент флорист).

Кто-то вообще отказывается от занятий какой-либо определённой деятельностью и живет на доход со сдачи квартиры и т.п.: «...я управленец, работал в крупной международной консалтинговой кампании, в какой-то момент понял, что больше не могу, устал. Взял перерыв на $з$ месяиа, потом на полгода, а потом вовсе понял, что больше не вернусъ. Сей- 
час живу за городом, квартиру в городе сдаю в аренду, сменил машину на более «простой» вариант. Ничем конкретно не занимаюсь, помогаю друзъям, пока меня всё устраивает...» (Владимир, 39 лет, в 2012 году переехал из Москвы в посёлок Московской области).

Были и те, кто из бизнесменов, юристов, инженеров, специалистов по маркетингу и рекламе ушли в фермеры, воспитатели в детском саду, разнорабочие:

«Непрерывная работа в режиме нон-стоп - это вредно для здоровъя, это скучно, это бессмысленная растрата своей жизни, это однообразно. Считаю, что дауниифтинг - для людей, которые реально любят и понимают жизнь, любят свочх близких и способны уйти от преклонения перед золотьм тельцом, бессмысленно тратя денъги на пустое...» (Станислав, 43 года, г. Новосибирск, до 2010 года руководитель департамента строительной компании, на данный момент занимается проектировкой загородньх домов, работает под заказ).

В контексте исследования организации трудовой деятельности дауншифтеров важными и интересньпи являются особенности решения финансовых вопросов. Формирование и использование денежных средств отчасти связаны с ведущей мотивацией дауншифтинга, а отчасти - с условиями жизнедеятельности. Как уже говорилось выше, основные источники дохода - средства от сдачи квартиры, удаленная работа (фриланс), мелкие заработки (продажа овощей со своего огорода, различного рода подработки) [2, с. 69]. Многие говорят о том, что стараются выстроить жизнь так, чтобы денег не требовалось совсем:

«Мы сами печем хлеб, овощи - со своего огорода, делаем заготовки на зиму, молоко, яйиа тоже свои, одежда пока кое-какая осталась из «прошлой жизни», пока совсем без денег не получается, но мы к этому стремимся» (Василий, 37 лет, в 2012 году вместе с семъёй (жена и дочь) переехали из Екатеринбурга в деревню Екатеринбургской области, в прошлом руководитель логистической компании, на данный момент безработный).

«Мы стараемся не тратить, статьи расхода, от которьх мы не можем отказаться: оплата Интернета, мобильной связи, электричество, налоги, бензин, ну и одежда... мясные продукты еще. Мы живем в экопоселении, здесь просто жить, потому что мы все друг другу помогаем, что-то вроде бартера, по строительству, по саду, с детьми посидеть u m.д.» (Антон, 40 лет, в 2009 году совместно с женой переехали из Москвы в экопоселение «Светлое» Московской области, в прошлом ведущий специалист отдела информационных технологий).

Отвечая на вопрос о тратах в месяц на человека, наши респонденты сходились на сумме в пределах от 10 тыс. руб. до 20 тыс. руб., но подчеркивали, что эта сумма достаточна для полноценного уровня жизни при наличии квартиры/дома и автомобиля:

«Я ранъше тратил на каждодневные нужды на себя бо тыс. руб. в месяи. А сейчас на 10 тыс. могу жать гораздо лучие, чем раньие на 6о... Представляю, как вы востринимаете эти слова - я сам раныше не представлял такого» (Владимир, 35 лет, соучредитель рекламного агентства, с 2013 года «свободный консультант-фрилансер»(определение интервьюируемого)).

«Деньги далеко не все решают, одной из важных причин для дауниифтинаа как раз является желание больше бывать с семьей. Хороиий тикник на природе, поездка, наличие свободного времени, отсутствие депрессии, связанной с тяжелой работой, - все это гораздо важнее бессмысленного «зарабатьвания» и «транжирования» денег» (Андрей, 39 лет, финансист, с 2013 года владелец интернет-магазина).

«Я утверждаю, что не 20 тыс., а 10 тыс. (рублей) на человека позволяют иметь высочайиее качество жизни, если есть хорошая квартира, машина и свободное время. Ранъше $я$ этого не понимал. Я сейчас питаюсь намного лучше, чемпитался, когда работал и транюнрил деньги. Я спокоен, у меня хорошее настроение, я свободен и получаю удовольствие от жизни. Яживу. А когда я работал за 150 тыс. я существовал, пределом моих мечтаний било тупо добраться до кровати и выспаться...» (Василий, 46 лет, в 2009 году уволился по собственному желанию с поста руководителя отдела продаж крупной международной кампании, на данный момент безработньй).

Более детальный анализ образа жизни дауншифтеров, расширение его контекста станет, на наш взгляд, важным шагом в понимании индивидуализации стилей жизни, изменений на рыпке труда, в сфере занятости и образования, трансформаций в обществе в целом. 


\section{ЛИТЕРАТУРА:}

1. Горц А. Нематериальное: знание, стоимость, капитал. М., 2010.

2. Козырева Л.Д., Овечкина Я.В. Дауншифтинг как объект социологического анализа // Вестник орловского государственного университета. 2012. №8. C. 68-71.

3. Малоун Т.У. Труд в новом столетии. Как новые формы бизнеса влияют на организации, стиль управления и вашу жизнь. М.: $3 \mathrm{AO}$ «Олимп бизнес», 2006.

4. Пинк Д. Нация свободных агентов: как новые независимые работники меняют жизнь Америки. М.: ИД «Секрет фирмы», 2005.

5. Харченко В.С. Ценностные предпочтения как основа формирования стиля жизни фрилансеров // Гуманитарные, социально-экономические и общественные науки. 2013. №1. С. 120-124.

6. Хэнди Ч. Время безрассудства. Искусство управления в организации будущего. СПб.: Питер, 2001.
7. Яковлева А.А. Потребительский ретретизм: альтернативный стиль жизни в обществе потребления // Журнал социологии и социальной антропологии. 2011. T. XIV. № 5. C. 192-201.

8. Hamilton C. Downshifting in Britain: A sea change in the pursuit of happiness // Discussion Paper. The Australia Institute. 2003. № 58 .

9. Hamilton C., Mail E. Downshifting in Australia: A sea change in the pursuit of happiness // Discussion Paper. The Australia Institute. 2003. № 5 0.

10. Ray P., Anderson S. The Cultural Creative `s. New York: Harmony Books, 2000.

11. Tan Ph. Leaving the rat race to get a life: a study of midlife career downshifting. Melbourne: Swinburne University of Technology, 2000 .

\section{REFERENCES:}

1. Gorts A. Immaterial: Knowledge, Value and Capital. Moscow, 2010.

2. Kozyreva L., Ovechkina Y. Downshifting as an object of sociological analysis. Vestnik of Orel state University. 2012. № 8. Pp. 68-71.

3. Malone Th. Work in the new century. As new forms of business affects the organization, management style and your life. Moscow: ZAO «Olimp business», 2006.

4. Pink D. Free Agent Nation: The Future of Working for Yourself. Moscow: Secret firmy, 2005 .

5. Kharchenko V. Values and preferences as a basis for the formation of lifestyle freelancers. Humanitarian, socio-economic and social sciences. 2013. №1. Pp. 120-124.

6. Handy Ch. The Time of desperation. The art of management in the organization of the future. $\mathrm{SPb}$ : Piter, 2001.
7. Yakovleva A. Consumer retreatism: alternative lifestyle in a consumer society. Journal of sociology and social anthropology. 2011. №5. Pp. 192-201.

8. Hamilton C. Downshifting in Britain: A sea change in the pursuit of happiness. Discussion Paper. The Australia Institute. 2003. № 58 .

9. Hamilton C., Mail E. Downshifting in Australia: A sea change in the pursuit of happiness. Discussion Paper. The Australia Institute. 2003. № 50.

10. Ray P., Anderson S. The Cultural Creative `s. New York: Harmony Books, 2000.

11. Tan Ph.Leaving the rat race togetalife: a study of midlife career downshifting. Melbourne: SwinburneUniversityofTechnology, 2000 